\title{
Sympathetic Predominance in Young Male White-Collar Workers with Mild to Moderate Hypertension
}

\author{
Toshio KOBAYASHI ${ }^{*}$, Noriko NISHIKIDO ${ }^{2}$, \\ Takayuki KAGEYAMA ${ }^{3}$ and Hiroshi KASHIWAZAKI ${ }^{4}$
}

\author{
${ }^{1}$ Department of Hygiene and Preventive Medicine, Fukushima Medical University, School of Medicine, Fukushima \\ 960-1295, Japan \\ ${ }^{2}$ Department of Community Health Nursing, St. Luke's College of Nursing, 10-1 Akashi-cho, Chuo-ku, Tokyo \\ 104-0044, Japan \\ ${ }^{3}$ Department of Mental Health and Psychiatric Nursing, Oita University of Nursing and Health Sciences, 2944-9 \\ Megusuno, Notsuharu, Oita 870-1201, Japan \\ ${ }^{4}$ Department of Human Sciences, School of Health Sciences, University of Occupational and Environmental \\ Health, 1-1 Iseigaoka, Yawatanishi-ku, Kitakyushu, Fukuoka 807-8555, Japan
}

Received October 2, 2000 and accepted December 28, 2000

\begin{abstract}
In order to investigate the difference in diurnal variation of autonomic control between young male mild to moderate hypertensive and normotensive white-collar workers, we accessed heart rate variability with ambulatory blood pressure for over 24 hours including work and sleep periods. Both mean systolic and diastolic blood pressures (SBP and DBP) were significantly (p<0.01) higher in hypertensives (HT, n=11) than normotensives (NT, n=11) in all phases, whereas heart rate was not different between them in any phase. Blood pressures during work period (on-duty) were significantly higher than those during non-work period (off-duty) in both NT and HT. High frequency $(\mathrm{HF} ; 0.15-0.40 \mathrm{~Hz})$ power showed a circadian pattern in phase with the sleep-wake cycle. Both HF and low frequency $(\mathrm{LF} ; 0.05-0.15 \mathrm{~Hz})$ powers in $\mathrm{HT}$ were significantly lower than that in NT during the sleep period $(p<0.05)$. LF/HF ratio showed a circadian pattern that was almost opposite of the pattern in HF power. Twenty-four-hour average LF/HF in HT was higher than that in NT $(p<0.05)$. Especially during on-duty, LF/HF in HT was significantly higher than in NT $(p<0.05)$. The increase of SBP and LF/HF from off-duty period to on-duty period ( $\triangle \mathrm{SBP}$ and $\triangle \mathrm{LF} / \mathrm{HF}$ ) showed significant positive correlation $(r=0.67, P<0.05)$ in $\mathrm{HT}$ group, suggesting that the SBP elevation during on-duty in HT may be coupled with sympathetic activation. These results suggest that HT showed significantly reduced parasympathetic control during sleep and an increased sympathetic activity especially during on-duty as compared with NT. Our findings imply that persistence of sympathodominant states together with reduced vagal activity in young mild to moderate hypertensive workers may be related to future cardiovascular disorders.
\end{abstract}

Key words: Circadian variation, Autonomic function, Heart rate variability, Hypertension, White-collar worker

*To whom correspondence should be addressed. 


\section{Introduction}

Hypertension is one of the major risk factors of ischemic heart disease. Thus far, several mechanisms in the genesis of hypertension have been proposed. In the early phase of young borderline hypertension, sympathetic drive to the heart and blood vessels is increased while parasympathetic tone is decreased ${ }^{1-3)}$, which probably contributes to the progression of cardiovascular diseases. It has been also reported that job strain relates to the elevation of blood pressure ${ }^{4)}$ and self-perceived psychological stress is an independent risk factor of coronary artery disease in middle-aged men ${ }^{5}$. Although previous data from controlled laboratory studies showed changes of stress hormones, such as epinephrine and norepinephrine, with many life stressors ${ }^{6,7)}$, there is little data describing the autonomic nervous changes among various active phases in a real life including the work period. Furthermore, the characteristics of autonomic nervous functions have not been reported in young mild to moderate hypertensive workers during various active phases including work and sleep periods. Determining the characteristics of autonomic changes for hypertensive workers is important in order to reduce the detrimental effects of work and/or life stresses on autonomic functions. In this study, we attempted to describe the diurnal variation of autonomic functions and blood pressure in young male white-collar workers with mild to moderate hypertension compared to normotensive workers in a software developing company in Japan.

\section{Materials and Methods}

\section{Study subjects}

The subjects were 11 mild to moderate hypertensives (HT; mean age $33.4 \pm 4.2 \mathrm{yrs}$, mean blood pressure $150.5 \pm 17.5$ / $94.7 \pm 8.8 \mathrm{mmHg}$ ) without any other medical disorder nor antihypertensive drugs and 11 normotensives (NT; mean age $33.5 \pm 4.0 \mathrm{yrs}$, mean blood pressure 118.5 $\pm 9.7 / 77.7 \pm$ $7.4 \mathrm{mmHg}$ ) young male white-collar workers. The subjects worked in a data processing and software development company in Tokyo, Japan. All of them were engaged in system engineering and programming, worked from 9:30 to $18: 30$, and frequently worked overtime until midnight. As cardiac parasympathetic activity indicated by heart rate variability changes with increasing age ${ }^{8-10)}$ and obesity ${ }^{10)}$, we selected the NT and HT subjects matching for age and body mass index (BMI). Subjects were requested to refrain from smoking and drinking alcohol on the experimental day in order to avoid their acute effects on autonomic nervous function $^{11,12)}$. Informed consent to participation in this study was obtained from each subject.

\section{Blood pressure and heart rate variability measurements}

Systolic and diastolic blood pressures (SBP and DBP) were measured with a sphygmomanometer on the right arm in a seated position after a five-minute rest. Two measurements were taken and averaged. All the subjects were classified as HT (mild to moderate hypertension) or NT according to the JNC V (Joint National Committee on Detection, Evaluation, and Treatment of High Blood Pressure) criteria ${ }^{13)}$. Standing height and body weight in clothing were measured. BMI was calculated as weight $(\mathrm{kg}) /$ height $(\mathrm{m})^{2}$.

Ambulatory blood pressure and electrocardiograms (ECG) monitoring (TM-2425; A\&D Co. Tokyo, Japan) were carried out on a weekday (from Tuesday to Thursday) for over 26 hours for each subject during study periods (from May to July 1997). Blood pressure was measured and recorded every 30 min by the cuff-oscillometric method. R-R interval data for 512 consecutive heartbeats were measured every 30-min as one segment for the same periods as blood pressure measurement. All the recordings started at approximately 8:30, and finished at 10:30 the next day. Data used in the subsequent analysis were started two hours after the beginning of measurements, in order to avoid initial effects of the experimental conditions on BP and heart rate. ECG was recorded on an analyzing processor TM-2425 through an ADconverter at a sampling rate of every 7.8 millisecond. Each $\mathrm{R}$ spike was detected with a preset threshold in order to measure $\mathrm{R}-\mathrm{R}$ intervals. R-R interval power spectra were computed with an analyzing processor TM-2425. Power spectral densities were computed by an autoregressive model and the magnitude of each spectral component was shown as the calculated power, expressed in $\mathrm{msec}^{2}$. The low frequency power spectrum (LF; $0.05-0.15 \mathrm{~Hz}$ ) band reflects both vasomotorial sympathetic and parasympathetic activities modulated by baroreflex sensitivity ${ }^{14,15)}$. The power spectrum band in high frequency (HF; $0.15-0.40 \mathrm{~Hz}$ ) reflects mainly vagal activity related to respiration ${ }^{14,16)}$. In this study, we adopted HF power as an index of cardiac parasympathetic nervous function, and the ratio of the power spectra in LF and $\mathrm{HF}(\mathrm{LF} / \mathrm{HF})$ as an index of sympathetic modulations which is considered to be reflective of sympathovagal balance ${ }^{17)}$.

Blood pressure and autonomic nervous function were calculated as average values during the wake and sleep periods. Wake period was further divided into work (onduty) and non-work (off-duty) periods. Information about overtime work per month in the last 3 months was also obtained from the subjects. 


\section{Statistical analysis}

Data are given as the mean \pm SD. The significance of differences between NT and HT was tested with unpaired ttest. The significance of difference between different activity phases within group was tested with paired t-test. A probability $\mathrm{P}<0.05$ was taken as significant.

\section{Results}

Physical characteristics of the subjects are shown in Table 1. Physical characteristics were not different between the two groups except for blood pressures. The number of current drinkers was higher in HT. Mean working hours and sleep

Table 1. Physical characteristics of normotensive (NT) and hypertensive (HT) subjects

\begin{tabular}{lcc}
\hline & NT & HT \\
\hline Number (n) & 11 & 11 \\
Age (yrs) & $33.5 \pm 4.0$ & $33.4 \pm 4.2$ \\
Height (cm) & $168.2 \pm 2.2$ & $172.3 \pm 5.1$ \\
Weight (kg) & $70.6 \pm 3.2$ & $75.3 \pm 5.1$ \\
Body mass index $\left(\mathrm{kg} / \mathrm{m}^{2}\right)$ & $24.9 \pm 1.3$ & $25.4 \pm 1.4$ \\
Systolic blood pressure (mmHg) & $118.5 \pm 9.7$ & $150.5 \pm 17.5^{* *}$ \\
Diastolic blood pressure (mmHg) & $77.7 \pm 7.4$ & $94.7 \pm 8.8^{* *}$ \\
Smoker/non smoker (n) & $4 / 7$ & $4 / 7$ \\
Drinker/non drinker (n) & $6 / 5$ & $10 / 1$ \\
\hline
\end{tabular}

$* * \mathrm{P}<0.01$ vs NT. Values are mean $\pm \mathrm{SD}$. hours in HT and NT in the experimental day were $11.1 \pm$ 2.0 vs. $11.1 \pm 1.6$ and $6.2 \pm 1.2$ vs. $5.8 \pm 1.4 \mathrm{hrs}$, respectively, which showed no difference between the two groups. The amount of overtime worked in the last 3 months in HT was $53.6 \pm 30.4 \mathrm{hrs} /$ month, which tended to be longer than that in NT ( $45.5 \pm 25.4 \mathrm{hrs} /$ month), but the difference was not significant.

Diurnal blood pressure changes of both NT and HT showed a circadian pattern following the sleep-wake cycle. SBP, DBP and heart rate (HR) values in the activity and sleep phases are shown in Table 2. Both SBP and DBP were significantly $(\mathrm{p}<0.01)$ higher in HT than NT during all phases, whereas HR was not significantly different between the two groups. SBP and DBP during on-duty were significantly higher than those during off-duty both in NT and HT $(\mathrm{p}<0.05$ or $\mathrm{p}<0.01$, respectively).

Figure 1 demonstrates the diurnal changes of HF power assessed by heart rate variability in NT and HT. HF power showed a circadian pattern following sleep-wake cycle. HF power in HT tended to be lower than in NT among various activity phases. Significantly decreased HF power in HT was observed $(\mathrm{p}<0.05)$ as compared to NT during the sleep period (Table 3). Diurnal variations of LF power in NT and HT are shown in Fig. 2. LF power also showed a circadian pattern in NT, but such pattern was less evident in HT, resulting in significantly decreased values $(\mathrm{p}<0.05)$ in HT during the sleep period (Table 3). Figure 3 illustrates the diurnal changes of LF/HF ratio. The LF/HF showed a

Table 2. Systolic/diastolic blood pressures and heart rate of normotensive (NT) and hypertensive (HT) subjects in the various activity phases

\begin{tabular}{|c|c|c|c|}
\hline & & NT $(n=11)$ & $\mathrm{HT}(\mathrm{n}=11)$ \\
\hline \multirow[t]{3}{*}{$24 \mathrm{~h}$} & $\mathrm{SBP}(\mathrm{mmHg})$ & $121.2 \pm 5.1$ & $140.1 \pm 12.3^{* *}$ \\
\hline & DBP (mmHg) & $74.7 \pm 4.8$ & $91.8 \pm 8.9^{* *}$ \\
\hline & HR (beat/min) & $71.8 \pm 6.9$ & $75.3 \pm 7.8$ \\
\hline \multirow[t]{3}{*}{ awake } & SBP & $128.3 \pm 5.9$ & $145.4 \pm 12.1 * *$ \\
\hline & DBP & $80.2 \pm 5.0$ & $96.7 \pm 8.5^{* *}$ \\
\hline & $\mathrm{HR}$ & $77.3 \pm 7.9$ & $80.1 \pm 8.0$ \\
\hline \multirow[t]{3}{*}{ on-duty } & SBP & $130.2 \pm 5.1$ & $146.9 \pm 11.4^{* *}$ \\
\hline & DBP & $81.3 \pm 5.4 \square$ & $98.7 \pm 8.0 * * \square$ \\
\hline & $\mathrm{HR}$ & $77.9 \pm 8.6 \quad$ \#\# & $80.3 \pm 8.6 \quad$ \\
\hline \multirow[t]{3}{*}{ off-duty } & SBP & $124.5 \pm 7.7 \longrightarrow$ & $142.7 \pm 14.3 * * \square$ \\
\hline & DBP & $77.8 \pm 5.6 \square$ & $93.1 \pm 9.9 * * \square$ \\
\hline & $\mathrm{HR}$ & $76.5 \pm 8.4$ & $80.3 \pm 9.2$ \\
\hline \multirow[t]{3}{*}{ sleep } & SBP & $102.8 \pm 5.5$ & $124.2 \pm 11.5^{* *}$ \\
\hline & DBP & $60.2 \pm 6.2$ & $77.4 \pm 8.9^{* *}$ \\
\hline & HR & $57.6 \pm 7.5$ & $61.8 \pm 8.7$ \\
\hline
\end{tabular}

**P<0.01 vs NT, \# $\mathrm{p}<0.05, \# \# \mathrm{p}<0.01$ between on-duty and off-duty. Values are mean $\pm \mathrm{SD}$. 


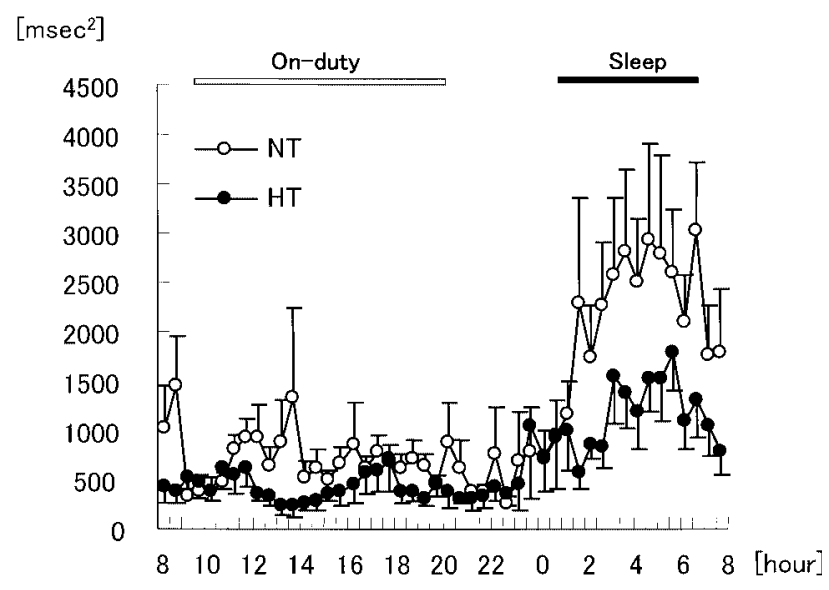

Fig. 1. Circadian variation of high frequency (HF) power (mean \pm SEM) in normotensive $(\bigcirc)$ and hypertensive $(\bigcirc)$ subjects. Horizontal bars indicate the mean on-duty $(\square)$ and sleep times ( $\boldsymbol{\square}$ ) of all subjects.

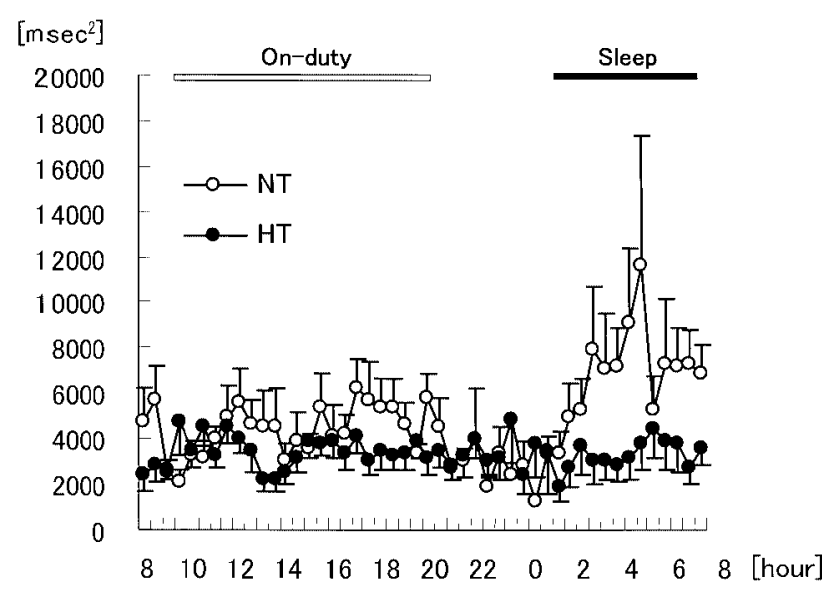

Fig. 2. Circadian variation of low frequency (LF) power (mean \pm SEM) in normotensive $(O)$ and hypertensive $(O)$ subjects. Horizontal bars indicate the mean on-duty ( $\square$ ) and sleep times ( $\boldsymbol{\square}$ ) of all subjects.

circadian pattern that was almost opposite of the pattern in HF power. Twenty-four-hour average LF/HF in HT was higher $(\mathrm{p}<0.05)$ than in NT (Table3). During work, LF/HF was again significantly higher $(\mathrm{p}<0.05)$ in HT as compared with NT. On the other hand, there was no difference between the two groups in HF/LF during off-duty or during the sleep period.

The correlation between the differences of $\operatorname{SBP}(\triangle \mathrm{SBP})$ between on-duty and off-duty and of LF/HF $(\Delta \mathrm{LF} / \mathrm{HF})$ in NT and HT are shown in Fig. 4. Significant positive correlation $(r=0.67 ; p<0.05)$ was observed between $\triangle \mathrm{SBP}$ and $\Delta \mathrm{LF} / \mathrm{HF}$ only in HT group.
Table 3. Autonomic nervous activities of normotensive (NT) and hypertensive (HT) subjects in the various activity phases

\begin{tabular}{llll}
\hline & & $\mathrm{NT}(\mathrm{n}=11)$ & $\mathrm{HT}(\mathrm{n}=11)$ \\
\hline \multirow{2}{*}{$24 \mathrm{~h}$} & $\ln (\mathrm{LF})$ & $8.22 \pm 0.55$ & $7.87 \pm 0.66$ \\
& $\ln (\mathrm{HF})$ & $6.65 \pm 0.71$ & $6.01 \pm 0.79$ \\
& $\ln (\mathrm{LF} / \mathrm{HF})$ & $1.79 \pm 0.29$ & $2.15 \pm 0.46^{*}$ \\
\hline \multirow{2}{*}{ awake } & $\ln (\mathrm{LF})$ & $8.09 \pm 0.59$ & $7.90 \pm 0.65$ \\
& $\ln (\mathrm{HF})$ & $6.17 \pm 0.72$ & $5.60 \pm 0.90$ \\
& $\ln (\mathrm{LF} / \mathrm{HF})$ & $2.02 \pm 0.33$ & $2.42 \pm 0.51^{*}$ \\
\hline \multirow{2}{*}{ on-duty } & $\ln (\mathrm{LF})$ & $8.18 \pm 0.60$ & $7.97 \pm 0.67$ \\
& $\ln (\mathrm{HF})$ & $6.26 \pm 0.69$ & $5.58 \pm 0.94$ \\
& $\ln (\mathrm{LF} / \mathrm{HF})$ & $1.99 \pm 0.31$ & $2.47 \pm 0.53^{*}$ \\
\hline \multirow{2}{*}{ off-duty } & $\ln (\mathrm{LF})$ & $7.83 \pm 0.64$ & $7.71 \pm 0.75$ \\
& $\ln (\mathrm{HF})$ & $5.93 \pm 0.95$ & $5.58 \pm 0.93$ \\
& $\ln (\mathrm{LF} / \mathrm{HF})$ & $2.06 \pm 0.41$ & $2.30 \pm 0.50$ \\
\hline \multirow{2}{*}{ sleep } & $\ln (\mathrm{LF})$ & $8.53 \pm 0.76$ & $7.74 \pm 0.76^{*}$ \\
& $\ln (\mathrm{HF})$ & $7.54 \pm 0.82$ & $6.86 \pm 0.68^{*}$ \\
& $\ln (\mathrm{LF} / \mathrm{HF})$ & $1.01 \pm 0.31$ & $0.99 \pm 0.49$ \\
\hline
\end{tabular}

${ }^{*} \mathrm{p}<0.05$ vs NT, \# $\mathrm{p}<0.05, \$ \mathrm{p}<0.1$ between on-duty and off-duty. Values are mean \pm SD.

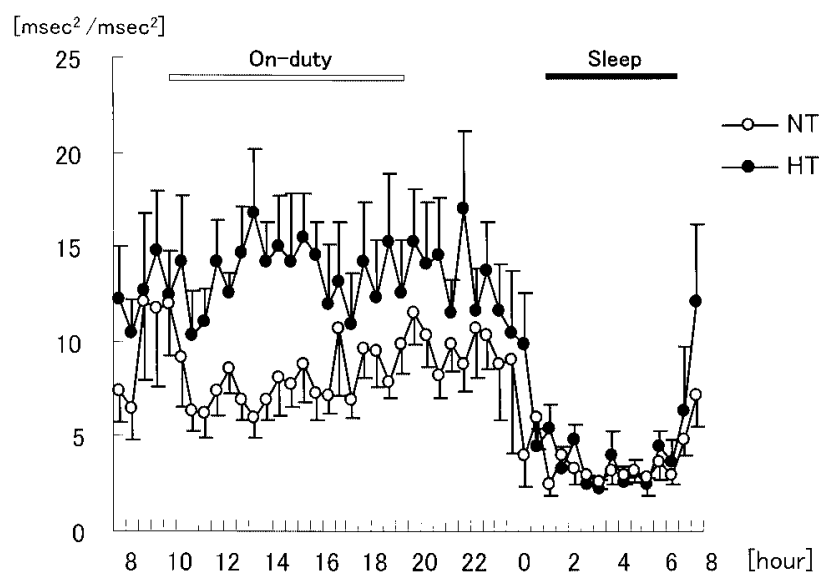

Fig. 3. Circadian variation of $L F / H F$ ratio (mean $\pm S E M)$ in normotensive $(O)$ and hypertensive $(\bigcirc)$ subjects.

Horizontal bars indicate the mean on-duty $(\square)$ and sleep times ( of all subjects.

\section{Discussion}

In this study, we assessed diurnal blood pressure and autonomic nervous changes in young male NT and untreated mild to moderate HT during a typical weekday, including the daily mental and/or physical work stress typical to a working period. We confirmed that diurnal changes of BP and autonomic nervous activities indicated by HF, LF power 

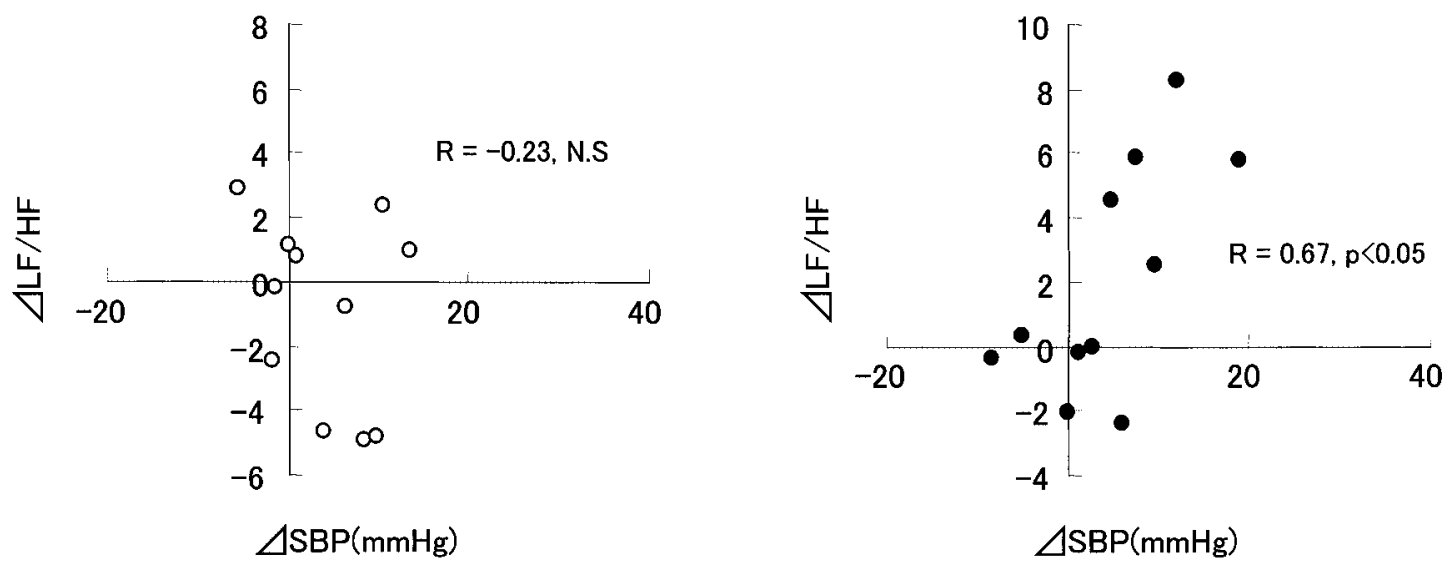

Fig. 4. Relation between $\Delta \mathrm{SBP}$ and $\Delta \mathrm{LF} / \mathrm{HF}$ in normotensive $(O)$ and hypertensive $(O)$ subjects. In hypertensive subjects, $\Delta \mathrm{LF} / \mathrm{HF}$ showed significant positive correlation with $\Delta \mathrm{SBP}$. However in normotensive subjects, the relation was not statistically significant.

and $\mathrm{LF} / \mathrm{HF}$ ratio showed a clear circadian pattern following the sleep-wake cycle in NT. These results are consistent with those of previous reports in normotensive workers ${ }^{18-20)}$. We also found an altered pattern of circadian neural control of heart rate in HT as compared to NT. Using spectral analysis of R-R intervals of heart rate ${ }^{14,21)}$, enhanced sympathetic activity and reduced vagal activity in essential hypertension compared with normotension was proposed ${ }^{22)}$. An altered pattern of circadian autonomic nervous control between normotension and mild hypertension was recognized by several studies ${ }^{23,24)}$. Guzzetti et al. ${ }^{23)}$ reported a reduced day-night oscillation in sympathetic activity in essential hypertension as compared with normotension. We also recognized reduced circadian oscillation of autonomic nervous changes in HT as expressed by HF and LF.

Patients with borderline hypertension have a high risk of developing sustained hypertension relative to the normotensive population. It is reported that about $20 \%$ of borderline hypertension will develop into a more advanced form of hypertension over 10 years ${ }^{25}$. In addition, cardiovascular hyperreactivity to mental stress ${ }^{26,27)}$ or physical stress $^{28,29)}$ has been reported to predict the onset of hypertension. The important findings in this study are that cardiac parasympathetic nervous activities were significantly depressed during sleep and sympathetic nervous activities were highly activated during awakefullness, especially during on-duty in HT as compared to NT. Itoh et al..$^{30)}$ reported that sympathetic activity assessed by $\mathrm{L} / \mathrm{H}$ response to mental arithmetic stress was larger in 30-year-old borderline hypertensives than normotensives under laboratory conditions. Our results indicate that sympathetic overactivity in young mild to moderate hypertensives is found especially during the working period, suggesting that the autonomic nervous response to job stress may function differently in HT and HT.

Moreover, we found a positive correlation between the changes of SBP and LF/HF ( $\triangle \mathrm{SBP}$ and $\Delta \mathrm{LF} / \mathrm{HF}$ ) from the off-duty period to the on-duty period, only in HT group. This suggests that elevation of blood pressure during onduty period might be coupled with enhanced sympathetic activity in the HT group. Our previous study ${ }^{31)}$ also revealed the association among self-reported job-stress, sleep quality and daytime autonomic activities in workers employed by the same company of this study. On the other hand, we identified that HF power during on-duty was significantly higher than during off-duty in NT with higher BP during on-duty compared to off-duty (Table 3). The reason of this inconsistent result is not clear. One possibility is that regulation of $\mathrm{BP}$ during on-duty may not predominantly depend on parasympathetic regulation. All of our subjects were white-collar workers, system engineers, who engaged in data processing and software development mainly in a sitting position. Therefore, posture and physical activity which would affect autonomic nervous function were not different between HT and NT during on-duty.

During the sleep period, we confirmed significantly reduced parasympathetic tone without changing sympathovagal balance in HT as compared with NT. Reduced HF power during sleep in HT compared to NT was also recognized in some studies ${ }^{23,24)}$. It was reported that reduced heart rate variability (reduced HF components) and baroreflex sensitivity were closely related to cardiac sudden death ${ }^{32,33)}$. Our findings of more reduced HF power in HT as compared with NT during sleep period implies increased cardiovascular 
risks in HT. In the present study, we did not obtain the data of sleep stages, which would affect cardiac autonomic control differently ${ }^{34,35)}$. But since the sleep structures have also been reported to be similar between $\mathrm{NT}$ and $\mathrm{HT}^{36)}$, it seems unlikely that the observed difference in autonomic control between NT and HT during sleep was not ascribed to the effects of sleep structures.

In conclusion, we confirmed in this study that diurnal changes of autonomic nervous activities showed altered pattern between NT and HT young male white-collar workers. We also recognized that young mild to moderate HT showed significantly reduced parasympathetic control compared to NT during sleep and that HT showed a sympathodominant state, especially during the on-duty period. These results imply that persistence of the sympathodominant state together with reduced vagal activity in young HT may be related to the progression of future cardiovascular disorders. Our findings presented in this study may be of help for improvement of work conditions, especially for mild to moderate hypertensive workers. Also, it will be necessary to conduct follow up study of these subjects in order to reveal more a detailed relationship between autonomic nervous and blood pressure profiles.

\section{References}

1) Folkow B (1982) Physiological aspects of primary hypertension. Physiol Rev 62, 347-504.

2) Amerena J, Julius $S$ (1995) The role of the autonomic nervous system in hypertension. Hypertens Res 18, 99 110.

3) Julius $S$, Nesbitt $S$ (1996) Sympathetic overactivity in hypertension. A moving target. Am J Hypertens 9, 113S$20 \mathrm{~S}$.

4) Schnall PL, Schwartz JE, Landsbergis PA, Warren K, Pickering TG (1992) Relation between job strain, alcohol, and ambulatory blood pressure. Hypertension 19, 488-94.

5) Rosengren A, Tibblin G, Wilhelmsen L (1991) Selfperceived psychological stress and incidence of coronary artery disease in middle-aged men. Am J Cardiol 68, 1171-5.

6) Pollack AC, Steklis HD (1986) Urinary catecholamines and stress in male and female police cadets. Hum Biol 58, 209-20.

7) Dimsdale JE, Ziegler MG (1991) What do plasma and urinary measures of catecholamines tell us about human response to stressors? Circulation $\mathbf{8 3}$ (Suppl), II36-II42.

8) Ziegler D, Laux G, Dannehl K, Spuler M, Muhlen H,
Mayer P, Gries FA (1992) Assessment of cardiovascular autonomic function: age-related normal ranges and reproducibility of spectral analysis, vector analysis, and standard tests of heart rate variation and blood pressure responses. Diabet Med 9, 166-75.

9) Murata K, Landrigan PJ, Araki S (1992) Effects of age, heart rate, gender, tobacco and alcohol ingestion on R-R interval variability in human ECG. J Auton Nerv Syst 37, 199-206.

10) Kageyama $T$, Nishikido N, Honda $Y$, Kurokawa $Y$, Imai H, Kobayashi T, Kaneko T, Kabuto M (1997) Effects of obesity, current smoking status, and alcohol consumption on heart rate variability in male whitecollar workers. Int Arch Occup Environ Health 69, 44754.

11) Hayano J, Yamada M, Sakakibara $Y$, Fujinami T, Yokoyama K, Watanabe Y, Takata K (1990) Shortand long-term effects of cigarette smoking on heart rate variability. Am J Cardiol 65, 84-8.

12) Murata $K$, Araki $S$, Yokoyama $K$, Sata F, Yamashita $K$, Ono Y (1994) Autonomic neurotoxicity of alcohol assessed by heart rate variability. J Auton Nerv Syst 48, 105-11.

13) Joint National Committee on Detection, Evaluation, and Treatment of High Blood Pressure (1993) The fifth report of the Joint National Committee on Detection, Evaluation, and Treatment of High Blood Pressure. Arch Intern Med 153, 154-83.

14) Akselrod S, Gordon D, Ubel FA, Shannon DC, Berger AC, Cohen RJ (1981) Power spectrum analysis of heart rate fluctuation: a quantitative probe of beat-to-beat cardiovascular control. Science 213, 220-2.

15) Madwed JB, Albrecht P, Mark RG, Cohen RJ (1989) Low-frequency oscillations in arterial pressure and heart rate: a simple computer model. Am J Physiol 256, H1573-79.

16) Berntson GG, Cacioppo JT, Quigley KS (1993) Respiratory sinus arrhythmia: autonomic origins, physiological mechanisms, and psychophysiological implications. Psychophysiology 30, 183-96.

17) Task Force of the European Society of Cardiology and the North American Society of Pacing and Electrophysiology (1996) Heart rate variability: standards of measurement, physiological interpretation and clinical use. Circulation 93, 1043-65.

18) Goto T, Yokoyama K, Araki T, Miura $T$, Saitoh H, Saitoh M, Satoh S (1994) Identical blood pressure levels and slower heart rates among nurses during night work and day work. J Hum Hypertens 8, 11-4. 
19) Kobayashi T, Matsuzaki I, Nishimura A, Murakami M (1996) Circadian blood pressure rhythm in shift workers: Study on blood pressure reduction during sleep. J Occup Health 38, 45-6.

20) Matsuzaki I, Nishimura A, Morita N, Satoh S, Kobayashi T, Murakami M (1996) Autonomic nervous activity changes due to shift-work: An evaluation by spectral components of heart rate variability. J Occup Health 38, 80-1.

21) Pagani M, Lombardi F, Guzzetti S, Rimoldi O, Furlan R, Pizzinelli P, Sandrone G, Malfatto G, Dell'Orto S, Piccaluga E (1986) Power spectral analysis of heart rate and arterial pressure variabilities as a marker of sympatho-vagal interaction in man and conscious dog. Circ Res 59, 178-93.

22) Guzzetti S, Piccaluga E, Casati R, Cerutti S, Lombardi F, Pagani M, Malliani A (1988) Sympathetic predominance in essential hypertension: a study employing spectral analysis of heart rate variability. $\mathrm{J}$ Hypertens 6, 711-7.

23) Guzzetti S, Dassi S, Pecis M, Casati R, Masu AM, Longoni P, Tinelli M, Cerutti S, Pagani M, Malliani A (1991) Altered pattern of circadian neural control of heart period in mild hypertension. J Hypertens 9, 8318.

24) Malliani A, Pagani M, Lombardi F, Cerutti S (1991) Cardiovascular neural regulation explored in the frequency domain. Circulation 84, 482-92.

25) Julius S, Schork MA (1971) Borderline hypertensiona critical review. J Chronic Dis 23, 723-54.

26) Falkner B, Onesti G, Hamstra B (1981) Stress response characteristics of adolescents with high genetic risk for essential hypertension: a five year follow-up. Clin Exp Hypertens 3, 583-91.

27) Von Eiff AW, Gogolin E, Jacobs U, Neus H (1985) Heart rate reactivity under mental stress as a predictor of blood pressure development in children. J Hypertens 3, S8991.
28) Dlin RA, Hanne N, Silverberg DS, Bar-Or O (1983) Follow-up of normotensive men with exaggerated blood pressure response to exercise. Am Heart J 106, 31620.

29) Benbassat J, Froom P (1986) Blood pressure response to exercise as a predictor of hypertension. Arch Intern Med 146, 2053-55.

30) Itoh H, Takeda K, Nakamura K, Fujita H, Uchida A, Kuwahara T, Takenaka K, Tanaka M, Nakata T, Sasaki S, Nakagawa M (1995) Young borderline hypertensives are hyperreactive to mental arithmetic stress: spectral analysis of R-R intervals. J Auton Nerv Syst 54, 15562.

31) Kageyama T, Nishikido N, Kobayashi T, Kurokawa $Y$, Kaneko T, Kabuto M (1998) Self-reported sleep quality, job stress, and daytime autonomic activities assessed in terms of short-term heart rate variability among male white-collar workers. Ind Health 36, 263-7.

32) Pozzati A, Pancaldi LG, Di Pasquale G, Pinelli G, Bugiardini R (1996) Transient sympathovagal imbalance triggers "ischemic" sudden death in patients undergoing electrocardiographic Holter monitoring. J Am Coll Cardiol 27, 847-52.

33) Schwartz PJ (1998) The autonomic nervous system and sudden death. Eur Heart J 19 (Suppl F), F72-80.

34) Vanoli E, Adamson PB, Ba-Lin, Pinna GD, Lazzara R, Orr WC (1995) Heart rate variability during specific sleep stages. A comparison of healthy subjects with patients after myocardial infarction. Circulation 91, 1918-22.

35) Elsenbruch S, Harnish MJ, Orr WC (1999) Heart rate variability during waking and sleep in healthy males and females. Sleep 22, 1067-71.

36) Frisina N, Pedulla M, Mento G, Morano E, Lanuzza B, Buemi M (1998) Normotensive offspring with nondipper hypertensive parents have abnormal sleep pattern. Blood Press 7, 76-80. 